\title{
Um Aplicativo Móvel Para Educação Ambiental
}

\author{
João Abreu ${ }^{1}$, João Willamy Sousa ${ }^{1}$, Matheus Lacerda ${ }^{1}$ \\ ${ }^{1}$ Bacharelado em Sistemas de Informação - Instituto Federal de Educação, Ciência e \\ Tecnologia do Ceará - (IFCE) Campus Crato - 63.115-500 - Crato - CE - Brazil \\ joaobrito0408@gmail.com, willamyse@gmail.com, the.matheus6egmail.com
}

\begin{abstract}
This work exposes steps taken to build a functional application, starting from the concept of mobile learning. The application helps teaching subjects related to biology and formation of an environmental awareness. The tool shows peculiarities of each tree species present in explored region.
\end{abstract}

Resumo. Este trabalho expõe as etapas realizadas para a construção de um aplicativo funcional, partindo do conceito de aprendizagem móvel. $O$ aplicativo auxilia no ensino de disciplinas relacionadas à biologia e na formação de uma consciência ambiental. A ferramenta tem a função de apresentar às peculiaridades de cada espécie arbórea presente na região explorada.

\section{Introdução}

O conhecimento da flora nativa de uma determinada região tem papel fundamental na definição de estratégias de conservação da biodiversidade. Através de um levantamento florístico, podem-se adquirir informações que sejam relevantes para preservação ambiental. Com grande importância, visto que contribui com dados técnicos para identificar a flora da região. Neste sentido, existe uma necessidade de compartilhar informações para a população de forma simples, interativa, acessível e acrescentando valor educativo sobre a flora do meio ambiente pesquisado.

Esse contexto justifica a criação de um aplicativo móvel, para ser utilizado como instrumento de auxílio à educação ambiental. Podendo o aplicativo, ser utilizado para auxiliar professores em disciplinas relacionadas à biologia e em aulas de campo. $\mathrm{O}$ objetivo deste trabalho é apresentar uma plataforma interativa, por meio de um aplicativo móvel, para despertar o aprendizado acerca da diversidade da flora nativa.

\section{Tecnologias na Educação}

$\mathrm{O}$ ambiente escolar tradicional geralmente se caracteriza por um aprendizado exaustivo e pouco interativo. De forma diferente, às aplicações móveis podem construir o conhecimento despertando o interesse das crianças, jovens e adultos sobre determinado assunto. Essas aplicações têm um papel importante, pois podem reverter matérias enfadonhas em conteúdos interessantes.

Neste sentido vários trabalhos buscam identificar em diversos contextos, melhorias na educação ambiental através do uso de aplicativos que utilizem tecnologia móvel. No trabalho Aplicativo para educação ambiental de [ROCHA and CRUZ and LEÃO 2015], desenvolvido com uso do QRcode para estudo em uma única área, destacase o uso do celular para obtenção de informações sobre árvores catalogadas. Diferentemente do QRFlora que adapta-se às mais diversas regiões onde o foco seja $o$ 
VI Congresso Brasileiro de Informática na Educação (CBIE 2017)

Anais do XXVIII Simpósio Brasileiro de Informática na Educação (SBIE 2017)

estudo das árvores, tendo como ponto forte gerar ambientes de aprendizagem identificando a localização e um conjunto de informações de cada árvore consultada, bem como a visualização da árvore através de uma imagem. Além de armazenar a geolocalização das arvores.

\subsection{Aprendizagem móvel}

A aprendizagem móvel (Mobile Learning) se destaca pela presença massiva de dispositivos móveis no cotidiano dos indivíduos. Trata-se da aprendizagem que acontece através do auxílio de dispositivos sem fios, como notebooks, smartphones ou tablets, [AMARAL and BARTHOLO and CAGNIN 2009] afirmam isso com tecnologias semelhantes.

As principais características da aprendizagem móvel são: o direcionamento individualizado; a facilidade para encontrar material didático; a dinâmica; e a interatividade. Esse conjunto de atributos quebram paradigmas e proporcionam uma nova experiência ao usuário, ou seja, "um aprendizado individualizado em qualquer lugar a qualquer momento" [FIGUEIRA and FREITAS and OLIVEIRA 2015, p.82].

\subsection{O QRFlora}

A ferramenta é organizada de forma que qualquer usuário que utilize um smartphone consiga navegar sem muita dificuldade. A imagem a seguir (Figura 1) demonstra a sua utilização: (1) O usuário realiza o login com suas credenciais, sendo levado para a página principal que apresenta uma série de menus, facilmente identificáveis; ao clicar no mapa (2) ele será direcionado ao mapa da região; na página de busca (3) o usuário pode acessar o as espécies arbóreas cadastradas; a qualquer momento, a partir da página principal, ele pode acessar o leitor de $Q R$ code (4); ao ler o código ele será levado às informações sobre a espécie.

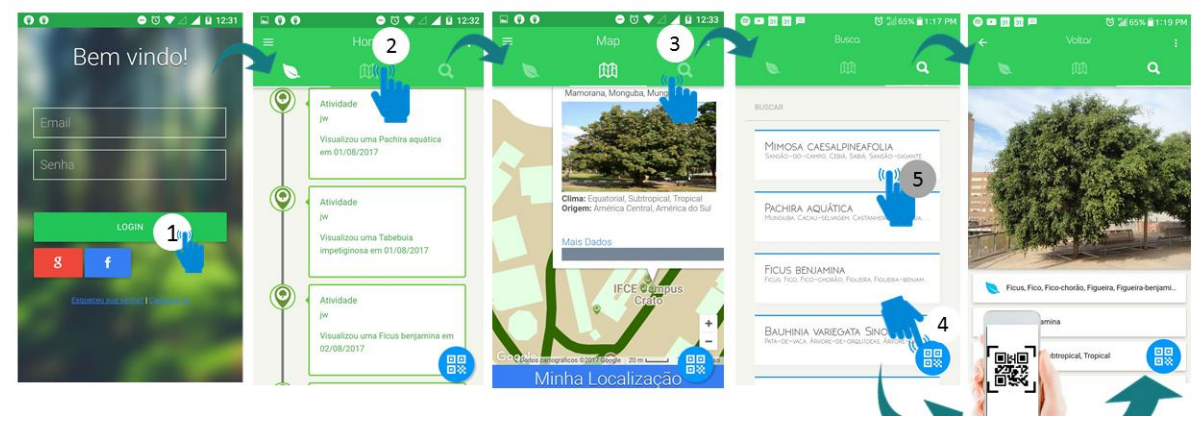

Figura 1. Exemplo da utilização do aplicativo

A utilização no meio educacional se manifesta quando da seguinte forma; o Professor como motivador, potencializa e fomenta o interesse do aprendiz a conhecer uma espécie, então o aluno, usando os métodos explicados pode identificar, pesquisar e até mesmo encontrar através do mapa a espécie desejada, abrindo novos horizontes a utilização da ferramenta dentro de uma zona educacional (Figura 1).

\section{Materiais e Métodos}

O desenvolvimento da aplicação foi realizado em etapas iterativas, verificando e melhorando a experiência do usuário (UX). Buscou-se sempre que o aprendiz tivesse 
acesso a informações precisas, de forma simples e rápida. Para tal foram desenvolvidos e testados vários protótipos junto ao ambiente de aplicação da ferramenta. O local escolhido para aplicar o projeto possui mais de 50 hectares de mata, sendo considerada a maior área de vegetação nativa na região, possuindo algumas espécies vegetais exóticas.

Para o protótipo descrito neste trabalho, foram cadastradas mais de trinta espécies arbóreas diferentes. Participaram da elaboração do aplicativo 4 (quatro) alunos do curso de Sistemas de Informações, 2(dois) alunos do curso de Agropecuária e 2 (dois) professores respectivamente das disciplinas de Informática Educativa do curso de Sistemas de Informação e Agroecologia do Curso de Agropecuária do Instituto Federal de Educação, Ciência e Tecnologia do Ceará (IFCE) - campus Crato .

\subsection{Desenvolvimento}

A primeira etapa do desenvolvimento consistiu da elaboração das ideias gerais do aplicativo, a criação de métodos de pesquisa, discussão sobre viabilidade e recebimento de dados iniciais para o início da pesquisa. Na segunda etapa foram escolhidas as tecnologias de desenvolvimento, feito o levantamento de requisitos, previsão de possíveis problemas e definição das etapas seguintes. $\mathrm{Na}$ etapa final foi realizado o desenvolvimento de dois módulos, um encarregado da inserção e modificação dos elementos (designado ao administrador) e o segundo próprio para o usuário, visando usabilidade e fácil utilização.

\section{Considerações Finais}

O aplicativo foi desenvolvido e pode ser acessado em Sistemas Operacionais Android. Podendo ser utilizado em outros contextos, utilizando seus recursos para mapear e identificar árvores de outras regiões, com o pré-requisito apenas que se faça o reconhecimento das espécies, o cadastro no sistema, a localização e a distribuição dos QRcodes. Quando feita esta catalogação da flora o aplicativo pode ser utilizado e consequentemente, aplicado para apoiar projetos em um cenário educacional. Contribuindo com a geração de ambientes imersivos de aprendizagem em uma determinada região.

\section{Referências}

Amaral, M. A., Bartholo, V. F. e Cagnin, M. I. (2009) "Uma Contribuição para a Adaptabilidade de Ambientes Virtuais de Aprendizagem para Dispositivos Móveis", Na: Revista Brasileira de Informática na Educação, v.17, n.2, p.36-47.

Figueira, L. B., Freitas, N. M. B. e Oliveira, A. G. P. (2015) "Aprendizado Móvel Aplicado Ao Ensino-Aprendizagem Acerca Do Patrimônio Cultural". Na: Nuevas Ideas en Informática Educativa TISE, Chile, n.1, p.81-88.

Rocha, L. A G., Cruz, F. M. e Leão, A. L.“Aplicativo para educação ambiental”. XI Fórum Ambiental da Alta Paulista, Brasil, v. 11, n. 4, 2015. 